\title{
Enseñanza de las Ciencias Biológicas, desde un enfoque anatómico, fisiológico y biofísico. La neurona y sus respuestas eléctricas como modelo de trabajo
}

\author{
Biological Science education, from an anatomical, physiological, and \\ biophysical approach. The neuron and its electrical responses as a working \\ model
}

\section{Hugo R. Molina Arroyo}

Benemérita Universidad Autónoma de Puebla hugo_molina_arroyo@hotmail.com

Montserrat Vázquez Balbuena

Benemérita Universidad Autónoma de Puebla mntsrrt@yahoo.com

\section{Resumen}

A partir del año 2008, la Benemérita Universidad Autónoma de Puebla implementa el Modelo Universitario Minerva (MUM), modelo fundamentado en el humanismo crítico y el construccionismo sociocultural, apostando por la implementación de nuevas TIC's en los procesos de aprendizaje, investigación y gestión. En este sentido la Escuela de Biología llevó a cabo una restructuración en su programa de estudios lo que permite garantizar, en todo momento, que el estudiante comprenda desde un punto de vista comparativo, al individuo y sus sistemas pasando por tejido y llegando hasta niveles de organización biológica celular y molecular a través del estudio de los movimientos transmembrana. Para cumplir con este objetivo los estudiantes deben cursar en orden jerárquico las materias de Morfología Animal, Fisiología Animal y finalmente Biofísica (entre otras). La experiencia aquí aportada gira en torno a la implementación, dentro de las materias antes mencionadas, de la utilización de la plataforma virtual "Moodle" y de "simuladores", herramientas mediante las cuales se fortalece el entorno de aprendizaje de los jóvenes universitarios. Finalmente se observó que el uso de plataformas y simuladores virtuales juegan un papel 
clave para lograr que los alumnos utilicen todos los recursos proporcionados y logren hacerse de su conocimiento y que este sea significativo.

Palabras clave: Moodle, Simuladores, Morfología Animal, neurona, electrofisiología neuronal

\section{Abstract}

From the year 2008, the Autonomous University of Puebla implements the Minerva University-Model (MUM), model based on the critical humanism and sociocultural constructionism, betting on the implementation of new ICT in learning, research, and management processes. In this sense the school of biology carried out a restructuring in its curriculum, to ensure at all times, that the student understands, from a comparative point of view, the individual and their systems through tissue and reaching levels of biological organisation cellular and molecular study of transmembrane movements. To meet this objective students are taken in hierarchical order the materials of Animal Morphology, Animal Physiology and Biophysics (among others). The experience provided here revolves around the implementation, within the above mentioned subjects, the use of virtual platform "Moodle", "simulators", tools by means of which the young University learning environment is strengthened. Finally it was noted the use of platforms and virtual simulators to play a key role for students to utilize all the resources provided and manage to obtain knowledge and find it meaningful.

Key words: Moodle, Simulators, Animal Morphology, Neuron, Neural electrophysiology

Fecha recepción: Febrero 2014 Fecha aceptación: Mayo 2014

\section{Introducción}

Las Tecnologías de la Información y la Comunicación (TIC's) juegan un papel muy importante en el Espacio Europeo de Educación Superior como docencia significativa, en el que el alumno es el sujeto activo y protagonista de su proceso formativo. El éxito o fracaso de las innovaciones educativas depende, en gran medida, de la manera en que los diferentes actores educativos interpreten, redefinen, filtren y den forma a los cambios propuestos por 
el Espacio Europeo de Educación Superior (Kahale Carrillo, 2011). Para conseguir un efecto positivo, es necesario que el profesor cuente con un conjunto de competencias, mediante una asignación correcta de las Tecnologías de la Información y la Comunicación a las diferentes facetas del proceso de enseñanza-aprendizaje.

El aprendizaje online se define como el uso de Internet para acceder a materiales de aprendizaje, con el fin de interactuar con el contenido y el profesor y adquirir, a su vez, conocimientos, significado personal y crecer desde la experiencia de aprendizaje (Ally, 2004, en Kahale Carrillo, 2011). Es decir, la formación en entorno virtual, conocida como e-learning, es la docencia no presencial que se realiza mediante plataformas o medios tecnológicos. No obstante, ello no significa que la educación presencial quede a extramuros de las TIC, sino todo lo contrario, pues también le es de gran interés contar con aquéllas, de tal forma que al conjuntarse surja la formación combinada, denominada b-learning, en la que se entrecruzan tanto elementos presenciales como virtuales (Kahale Carrillo, 2011).

En el año 2008 la Benemérita Universidad Autónoma de Puebla (BUAP), concreta el Modelo Universitario Minerva (MUM), modelo fundamentado en el humanismo crítico y el construccionismo sociocultural, apostando por la implementación de nuevas TIC's en los procesos de aprendizaje, investigación y gestión. Dos años después (2010) la Vicerrectoría de Docencia de la BUAP conforma la Escuela de Formación Docente y Desarrollo Académico, la cual oferta programas de actualización docente. Para esto, contempla un programa de formación integral que incluye capacitación inicial, continua y de profesionalización en el área didáctico-pedagógica.

Como resultado de los cursos de aprendizaje antes mencionados, en el otoño del mismo año, la Escuela de Biología de la BUAP implementa la utilización en sus aulas de la plataforma Moodle, aplicación web de tipo "Ambiente Educativo Virtual", a partir de la cual los docentes forman comunidades de aprendizaje en línea. Una de las ventajas que tienen los ambientes educativos virtuales es la de permitir la comunicación privada entre los involucrados, al mismo tiempo que se apuntala la interacción grupal. Cabe señalar que el servidor para esta aplicación se ubica en la misma Unidad Académica, bajo la 
administración del personal del área de cómputo. Cuando se habla de la aplicación "Moodle" (Modular Object-Oriented Dynamic Learning Environment) o Entorno Modular de Aprendizaje Dinámico Orientado a Objetos, se hace referencia a una "plataforma tecnológica" o sistema de gestión de cursos sin costo que aparece en el año 2002 gracias a su creador, el profesor Martín Doigimas, administrador de WebCT en la Universidad de Curtin, Australia.

\section{Desarrollo de contenidos}

La neurona y sus respuestas eléctricas como modelo de trabajo el caso de la Escuela de Biología de la BUAP

Como ya se mencionó, la presente experiencia docente se llevó a cabo en las aulas de la Escuela de Biología de la BUAP. Esta Unidad Académica oferta dos licenciaturas, la Licenciatura en Biotecnología (de reciente creación) y la Licenciatura en Biología (con más de 25 años de experiencia), la cual se caracteriza por ser de modalidad educativa presencial, con dos niveles en su mapa curricular, el Básico y el Formativo. Esta licenciatura presenta dos ejes, por un lado el denominado "Biología Experimental” y por el otro el llamado "Biología de los Grupos de Organismos" los cuales, tal como lo indica su nombre, se conforman por una serie de materias que robustecen aspectos formativos hacia el desarrollo del quehacer biológico en el campo o bien en el laboratorio. En específico, dentro del Área de Morfofisiología Experimental se brindan las materias de Morfología Animal y Fisiología Animal a Nivel básico, y la materia de Biofísica del nivel formativo.

Desde la fundación de la Escuela de Biología (en 1987) a la fecha, se puede observar una clara tendencia: cada año, un alto número de alumnos cuyos estudios estuvieron concentrados en el área de 'Biología experimental' cursan, como último plan de estudios del nivel formativo, la materia de Neurobiología. Por desgracia, la realidad es que para la mayoría, su formación tanto teórica como práctica en el campo de la Fisiología y la Biofísica, disciplinas fundamentales para un claro entendimiento de los mecanismos básicos operantes en el funcionamiento neuronal, es deficiente (en gran medida) a causa de la imposibilidad de acceso al equipamiento que encontrarán como medio de análisis de las células nerviosas. 


\section{Abordaje desde el punto de vista anatómico-fisiológico}

En esta primera parte del trabajo se hace referencia a utilización de la plataforma Moodle en la impartición del tema "Sistema nervioso y órganos de los sentidos", correspondiente a la Unidad 9 de la Materia Morfología Animal de la Licenciatura en Biología de la BUAP, con lo cual se ejemplifica la promoción de una pedagogía constructivista y social, toda vez que se observa colaboración, realización de actividades y reflexiones criticas, entre otras características. Todas estas actividades se llevan a cabo como complemento del aprendizaje presencial al que está sujeta la materia antes mencionada. La utilización de Moodle se llevó a cabo durante la impartición de los cursos correspondientes a los periodos de primavera y otoño del año 2010 hasta el período de otoño de 2012.

Ahora bien, nosotros partimos de una premisa importante. En este caso, del hecho de que los estudiantes de la licenciatura en Biología cursan, durante los primeros cuatrimestres, la materia de "Desarrollo de Habilidades en el uso de la Tecnología, la información y la Comunicación (DHTIC)”, perteneciente al Área de Formación General Universitaria. En esta materia, se les instruye en la manejo de plataformas de educación electrónica como son Moodle y/o Blackboard. En ambos casos se le exige al estudiante una serie de cambios en el proceso de aprendizaje, así como el cambio de roles entre los "participantes". El docente, que asume el papel de guía, moderador u orientador virtual y el estudiante, quien construye sus conocimientos alcanzando el nivel exigido en este escenario educativo. Sin embargo, no es sino hasta la implementación y práctica real de estas herramientas en materias "formales" como son las antes mencionadas cuando el alumno demuestra y aplica sus destrezas.

Si bien dentro de cualquier curso el docente es quien tiene el control de las opciones, el Moodle es muy flexible en cuanto a las actividades que se pueden desarrollar a partir de los módulos, los cuales a través de "materiales o recursos", "foros", "cuestionarios", "Glosarios" y "tareas" (entre otros) permiten incrementar los medios que el estudiante operará para hacerse de la información que le permita forjar su propio conocimiento. 
Con la plataforma establecida y con el acceso de los estudiantes a la misma se dio inicio al desarrollo del tema "Sistema Nervioso". Para esto se suministraron algunos "recursos" a los estudiantes, los cuales consistieron, en primera instancia, del plan de estudios de la materia (en formato Word) incluyendo la bibliografía básica y complementaria, la cual debió ser consultada previo a la clase. Así mismo, se puso a disposición de los jóvenes de una serie de presentaciones con el editor PowerPoint de Microsoft $\subset$. Esta herramienta brinda texto esquematizado, lo que permite abordar el tema, en este caso, de lo general a lo particular. Es decir, el abordaje fue partir de lo macro al señalar al Sistema Nervioso Central y al Sistema Nervioso Periférico hasta la anatomía de las células constituyentes, esto sin perder definición en las imágenes. Si bien las presentaciones antes mencionadas son un resumen del tema, destaca su disponibilidad permanente para el estudiante sin necesidad del gasto de papel, esto claro apuntalado con su lectura previa y la explicación del docente. Con las imágenes en pantalla se establece cómo el Sistema Nervioso está constituido por el Sistema Nervioso Central (SNC) y el Sistema Nervioso Periférico (SNP), el primero de ellos compuesto por encéfalo y médula espinal y el segundo por los nervios y ganglios. En todos los casos unificado por sus características más importantes (como tejido nervioso), la excitación y la conductividad (Kardong, 2011).

Como ya se mencionó una parte del SNC es el encéfalo, constituido por el procencéfalo, el mesencéfalo y el romboencéfalo. En el primero de ellos destaca la porción del cerebro en donde se ubican dos pequeñas zonas que regulan importantes funciones automáticas del organismo: el tálamo y el hipotálamo. Estas dos estructuras están situadas entre el llamado cuerpo calloso, la protuberancia y el bulbo raquídeo. Desde el punto de vista fisiológico al tálamo pasan todos los estímulos sensoriales que llegan al cerebro (excepción del olfato) antes de transmitirlos a la corteza cerebral y hacerlos conscientes. Por su parte, el hipotálamo está formado por núcleos donde se dirigen funciones vitales como la temperatura corporal, el apetito, la sed y los latidos del corazón. Así mismo regula algunas de las funciones de la hipófisis, una de las glándulas más importantes del cuerpo la cual se ubica en la cavidad del hueso esfenoides llamada silla turca (Kardong, 2011). En este punto la plataforma se enriquece con más recursos, tal es el caso de "material Web", incluyendo "páginas" o "direcciones electrónicas" de videos que permitan, mediante animaciones tridimensionales, lograr que se esclarezca y se analice a profundidad la relación anatómica 
entre las partes mencionadas. Desde luego la utilización de modelos anatómicos es básica en este sentido.

Continuando con la médula espinal se indica que la misma comienza en el orificio occipital del cráneo, donde se une directamente al bulbo raquídeo y llega hasta las vértebras lumbares. La médula espinal es la vía de comunicación del SNC, y como es una vía de mucho "tráfico" tiene un doble sentido de circulación: la circulación sensitiva o aferente, que desde el todo el cuerpo conduce estímulos hacia el encéfalo,y la circulación motora o eferente, que lleva las órdenes del encéfalo a todo el organismo. Con la cantidad de lenguaje científico utilizado, en este punto entra en juego otra ventaja de la plataforma Moodle, al permitir crear y mantener la lista de definiciones que se utiliza como "glosario", mismo que se deberá incrementar con el avance de los temas permitiendo el desarrollo de la comunicación entre pares.

Una vez analizada la anatomía básica del SNC se da inicio al estudio del SNP, el cual está constituido por ese apartado de células nerviosas que se ubican fuera del SNC. El SNP esta compuesto por doce pares de nervios craneales y 31 de nervios espinales o raquídeos que salen de la médula espinal. Estos últimos se dividen en cervicales, dorsales, lumbares, y sacros, atendiendo a la región de la columna vertebral de la cual surgen. Nuevamente se apuntala el texto esquematizado con modelos anatómicos y la utilización de "material Web" a través de videos, lo que le permite al estudiante comprender la anatomía funcional de los pares de nervios craneales y espinales en un aprendizaje significativo. Así mismo, ahora el alumno comprende cómo la división entre el SNC y el SNP es netamente anatómica.

Como se menciono al inicio de este trabajo se parte de un nivel de organización biológica de sistemas y órganos, se menciona brevemente el de tejido y se da paso al nivel celular. En este sentido se trata de que los estudiantes comprendan que las secciones antes

mencionadas tienen como base constitucional redes de células nombradas "neuronas", acompañadas por las células "glía” o "células neuroglía”. Estas últimas con una subdivisión en atrocitos, microglía, oligodendroglía y células ependimales. 
Se reconoce que anatómicamente una neurona se encuentra formada por el cuerpo o soma, las dendritas y por el axón. En este tema las imágenes provenientes de cortes histológicos permite, acompañado de imágenes de textos especializados, que se observe y se comparen los diferentes tipos de neuronas con base en el número de extensiones (unipolares, bipolares y multipolares). Estas imágenes y textos especializados pueden estar anclados a la plataforma o bien mediante ligas disponibles de poder ser consultados por el estudiante desde el aula, o cualquier otro sitio en el que se encuentre realizando su análisis.

Para concluir el estudio de las neuronas se debe considerar que la división anatómica de los sistemas va acompañada de un lenguaje acertado, por ejemplo. Cuando se presenta un conjunto de axones en una sola vía al interior del SNC, se denominará tracto nervioso o vía, por otro lado si es un conjunto que se encuentra en el SNP, se denominará nervio. Otro ejemplo es cuando varios cuerpos celulares se unen o se reúnen al interior del SNC, se denominará núcleo, cuando ésta reunión se encuentra en el SNP, se denomina; ganglios. En este caso la utilización del "chat" o "foros" de conversación desde la plataforma Moodle permite la interacción de los participantes en tiempo real para discutir lo aprendido y solucionar dudas.

A través de presentaciones con diapositivas, acompañadas de videos, animaciones (extraídas de las páginas electrónicas de diversos textos de consulta en la materia (http://bcs.wiley.com/; http://highered.mcgraw-hill.com/; http://bcs.whfreeman.com). y/o la lectura de artículos de divulgación (en español), se introduce a los alumnos en el estudio de la composición de la membrana plasmática celular, de acuerdo con el modelo de Singer y Nicolson (1972). Este modelo describe la membrana plasmática como un mosaico fluido que contiene diversas proteínas insertadas en una matriz de fosfolípidos. Los fosfolípidos en la membrana forman una bicapa lipídica con las cabezas polares dirigidas hacia el exterior y las colas hidrofóbicas hacia el interior de la bicapa.

Posteriormente, se solicita a los alumnos que realicen una "tarea" (p.ej. un mapa conceptual), que permita calificar mediante el trabajo enviado la búsqueda de la 
información, el grado de entendimiento y la capacidad de síntesis. Esta técnica se emplea sobre todo en los tópicos finales, el Sistema Nervioso Simpático y Parasimpático.

Cabe señalar que la parte práctica es fundamental en esta materia por lo que se debe planificar de tal manera que las horas en laboratorio sean aprovechadas al máximo. Con este fin se provee al estudiante en la plataforma de TODAS las prácticas que se llevaran a cabo a lo largo del curso. Esto le permite conocer la información que se proporciona y la que se solicita en las mismas, comprendiendo perfectamente para qué se presenta el día de su desarrollo, entiéndase material y equipo solicitado. Desde luego se incluyen reglamentos y matrices para el desarrollo durante la práctica y para la entrega de la misma.

Finalmente si se considera propicio se puede generar un examen, el cual estará apuntalado por "cuestionarios" previos o bien solo uno final en carácter de examen realizado de diferente manera en la plataforma: repuesta múltiple, verdadero o falso, o bien respuesta cortas etc. Para esto se puede partir de una base de datos de preguntas almacenadas. Los cuestionarios pueden tener un límite de tiempo, determinado por consenso de acuerdo con la complejidad del tema a evaluar, ser resueltos.

\section{Abordaje desde el punto de vista fisiológico-biofísico}

Todo lo aprendido por los alumnos hasta este momento en sus cursos de "Morfología animal" y "Fisiología Animal" son retomados en el curso de "Biofísica" para 'reconstruir' la membrana plasmática neuronal como un modelo eléctrico equivalente de resistores y capacitores acoplados en paralelo. Para lograrlo, se añade una unidad sobre "Introducción a los fundamentos de la electricidad" (corriente, voltaje, resistencia, capacitancia, conductancia, etc.), y cada uno de los conceptos analizados se aterriza a su equivalente funcional biológico en la membrana. Esta unidad introductoria se ofrece mediante una presentación con diapositivas, acompañada de múltiples vídeos, animaciones, simulaciones y ejercicios numéricos de las ecuaciones abordadas; con todo ello se pretende lograr que el alumno comprenda los principios básicos que le permitan el entendimiento de los procesos de excitabilidad celular. 
El problema radica, principalmente, en que los dispositivos requeridos para la enseñanza de técnicas de análisis del funcionamiento de las neuronas (osciloscopios, estimuladores, generadores de funciones, etc.) tienen un costo elevado y en México, como en gran parte de Latinoamérica, estos precios alcanzan niveles prohibitivos para la mayoría de las instituciones públicas y privadas que imparten la licenciatura en Biología y carreras relacionadas. Aunado a ello, la inversión en uno de estos equipos no se justifica dado el número de alumnos y días de uso que se requieren, cada semestre, en este curso.

Una alternativa distinta para el aprendizaje, e incluso el entrenamiento en el uso de equipos sofisticados, de la electrofisiología neuronal es el uso de simuladores. En países desarrollados, el concepto de educación inmersiva se está instalando paulatinamente a lo largo de las distintas redes curriculares. Este concepto plantea un entorno de aprendizaje que utiliza simuladores para transferir conceptos teóricos y prácticos a sus alumnos (Chiang y cols., 2011). Existen diversas experiencias realizadas en establecimientos educacionales (colegios y universidades), así como otros establecimientos de educación informal (museos y bibliotecas) principalmente en Estados Unidos y Europa, que han utilizado simuladores para transferir conceptos de Física, Matemáticas, Ecología (Barab, Sadler, Heiselt, Hickey y Zuiker, 2007), Medicina (Potti, 2007; Salas \& Ardanza, 1995) e Historia (Roussou, 2000) a los alumnos (citado en Chiang y cols., 2011).

Por ello, esta sección tiene por objeto aportar mi experiencia y reflexiones en la utilización conjunta de animaciones, resolución de ejercicios numéricos y simuladores para la enseñanza del 'Potencial de Membrana (PM) neuronal', desde el punto de vista fisiológico y biofísico, a nivel de pregrado en la Licenciatura en Biología de la Escuela de Biología de la BUAP.

El estudio de los mecanismos que originan y mantienen la constancia del PM neuronal es particularmente importante en la neurobiología pues de su entendimiento se deriva el de las respuestas eléctricas que puede generar una neurona ante un estímulo, hasta aterrizar en la generación del impulso nervioso, mecanismo de comunicación intercelular por excelencia de las células nerviosas. 
Para tratar este tema se requiere que el alumno maneje con facilidad algunos tópicos: gradiente electroquímico, transporte activo transmembrana y tipos de canales iónicos (particularmente los dependientes de voltaje). Sin embargo, el problema que, en mi experiencia, he encontrado al abordarlos es que los alumnos los han visto previamente de modo superficial ( $\sin$ ahondar en la base física que rige la dirección de los movimientos transmembrana, por ejemplo) y 'poco’ visual.

Actualmente, en la educación la proyección de montajes audiovisuales de diapositivas mediante algún programa informático (Power Point, por ejemplo) pueden integrarse en las programaciones didácticas de cualquier curso o acción formativa, como complemento de los materiales escritos o del libro de texto. Estos montajes permiten concebir una enseñanza más dinámica, que incorpora junto al libro de texto y la pizarra, otros recursos didácticos motivadores e impactantes (Aguaded Gómez y Martínez-Salanova, 1998). Por ello, para el abordaje fisiológico teórico de estos conceptos he recurrido al uso de imágenes donde se esquematice el funcionamiento de estos mecanismos, extraídas de libros tales como Molecular Cell Biology (Lodish H. y cols., 2003) o Molecular Biology of the Cell (Alberts B. y cols., 2007).

Por otro lado, hay que reconocer que este uso tradicional de las diapositivas en las aulas, no ha venido acompañado en muchos casos, de un cambio de la metodología tradicional de enseñanza, ya que los docentes han seguido impartiendo exclusivamente sus clases magistrales, adornadas con dicho soporte visual, pero cambiando poco o nada la metodología. Luego entonces toda proyección debiera responder a un planificación didáctica que no tiene que ser laboriosa, pero sí explícita y compartida por un equipo de trabajo o seminario que incorpore actividades previas de los alumnos, así como trabajos de post-proyección que permitan una profundización e interpretación crítica tras ver la serie de diapositivas (Aguaded Gómez y Martínez-Salanova, 1998). Considerando esto, las proyecciones temáticas las acompaño de animaciones ofrecidas por los portales de servicios de desarrollo de material multimedia (http://www.sumanasinc.com/) y los de diversos 
textos de consulta en la materia (http://bcs.wiley.com/; http://highered.mcgraw-hill.com/; http://bcs.whfreeman.com).

Una vez que los alumnos han comprendido cómo operan estos movimientos transmebrana y que éstos generan los gradientes iónicos usuales de las células (enfatizando el caso de las neuronas), ahora estamos preparados para introducir el concepto de Potencial de Equilibrio de un ión (Ex), desde el punto de vista biofísico. Después de revisar las consideraciones teóricas necesarias mediante la utilización de proyecciones con esquemas explicativos de libros tales como Fundamentals of Physics (Halliday D. y cols., 2001), así como animaciones ofrecidas por los portales de diversos textos de consulta, se procede a la derivación de la Ecuación de Nernst, apoyándome en libros de texto como Temas de Biofísica (Parisi M., 2004).

En la parte práctica se recurre a la resolución manual de ejercicios aplicando esta fórmula para diferentes tipos celulares (incluyendo la neurona). Los valores de la concentración intra- y extracelular de los iones usados en los ejercicios se extraen de libros sobre neurobiología (por ejemplo, Principles of Neuroscience, Kandel E. y cols., 2004; Ionic channels of excitable membranes, Hille B., 1992) para que los alumnos se vayan familiarizando con la consulta de estos textos.

Posterior a este paso, se busca lograr que los alumnos comprendan que la membrana celular no es permeable solamente a una especie iónica $(\mathrm{K}+)$ sino también al $\mathrm{Na}+\mathrm{y}$ al $\mathrm{Cl}$ - (en grados distintos) con la consecuencia de que el PM (de ahora en adelante, Vm) es una diferencia de potencial eléctrico intracelular cuyo valor no corresponde a ningún Ex de un ion en particular, sino que depende de una especie de 'equilibrio dinámico' que debe establecerse entre las fuerzas del gradiente electroquímico de estos 3 iones, de modo que representa aquel valor de voltaje de membrana en el cual el flujo neto de los 3 iones está en equilibrio. ¿Pero para qué deben tener este concepto bien claro? Pues porque todas las señales eléctricas (o sea las respuestas generadas por las neuronas) involucran breves cambios del valor del PM en reposo, debido a alteraciones en el flujo de corriente eléctrica a través de la membrana celular resultado de la apertura y cierre de los canales iónicos 
inmersos en ella (Kandel y cols., 2000). Se utilizan para eso proyecciones con esquemas explicativos, y se procede a la derivación de la ecuación de Goldman-Hodgkin-Katz (GHK), apoyándome en libros de texto como el de Parisi (2004). En mi experiencia, es en este momento donde el uso de simuladores juega un papel clave para lograr que los alumnos utilicen todos los conceptos previamente analizados y los 'amalgamen' para lograr formular en sus propias palabras el mecanismo de acción de un fenómeno fisiológico: el PMR. Con este fin, como actividad intra- y extramuros se les pide a los alumnos que, de manera individual, usen diversos simuladores tales como PotMem (CSoto E., 1989) y The NERNST/GOLDMAN equation simulator (@Arizona Board of Regents, 2013).

Afrontaré particularmente el uso del programa PotMem@ puesto que fue desarrollado por un investigador del Instituto de Fisiología de la BUAP, el Dr. Enrique Soto Eguibar, lo cual les sirve a los alumnos para darse cuenta que también en México se puede desarrollar software sencillo pero altamente efectivo en la enseñanza de la electrofisiología neuronal. El PotMem $@$ es una simulación computacional de la generación del potencial de membrana neuronal. Tiene como características permitirle al usuario variar ampliamente las concetraciones intra- y extracelulares de los iones $\mathrm{Na}+, \mathrm{K}+\mathrm{y} \mathrm{Cl}-$, y determinar el $\mathrm{Vm}$ (usando la ec. GHK) y el Ex (usando la ec. Nernst) para cada ión. Considera el coeficiente de permeabilidad (Px) para cada uno, que puede variarse, y también permite modificar la temperatura a la que se realiza el 'experimento'. En la pantalla, todas esta modificaciones se resumen en un gráfico del Vm que visualmente permite al usuario ubicar la 'posición' del Ex de cada ión respecto a los otros 2 iones, y respecto al Vm resultante. Las ventajas que este simulador ofrece incluyen: 1) en un recuadro, se esquematiza la dirección y magnitud de la fuerza del gradiente electroquímico que 'siente' cada ión a través de la membrana celular, en forma de flechas que cambian (aumentan o disminuyen) y se mueven (entrando o saliendo) según se modifiquen los diversos parámetros. Esto permite al usuario visualizar que en ciertas condiciones, la dirección del flujo de un ión dado incluso puede llegar a revertirse, lo que funcionalmente trae grandes repercusiones para la célula; 2) obtener curvas concentración-voltaje en cualquier momento, que pueden imprimirse; 3) el usuario puede seleccionar una opción de 'fijación de voltaje' (voltage-clamp) que le permite imponer un cierto valor de PM a la neurona y estudiar la fuerza del gradiente 
electroquímico resultante para cada ión (Fig. 1). Particularmente, esta opción es muy útil pues permite la entrada natural al campo de la neurobiología, en donde la invención de esta técnica por A. Hodgking y A. Huxley les permitió, en 1952, decribir un modelo matemático que, al explicar los mecanismos iónicos subyacentes, describe cómo el potencial de acción de las neuronas es iniciado y propagado en el axón gigante de calamar, Loligo spp. Esta bellísima y elegante serie de experimentos les permitiría recibir en 1963 el Premio Nobel en Fisiología o Medicina. Entre los inconvenientes del programa tenemos que: 1) sólo se pueden hacer 'experimentos' usando las concentraciones iónicas de 3 neuronas distintas (axón gigante de calamar, nervio de gato y nervio de rana); y 2) no se ha actualizado para adecuarse a los nuevos sistemas operativos existentes, por lo que únicamente puede instalarse y ejecutarse satisfactoriamente en versiones de Windows@ 95 hasta Windows $\bigodot$ XP (aunque se puede usar aún en Windows@ 7 pero sólo para la versión Starter edition, que es la más sencilla y limitada).

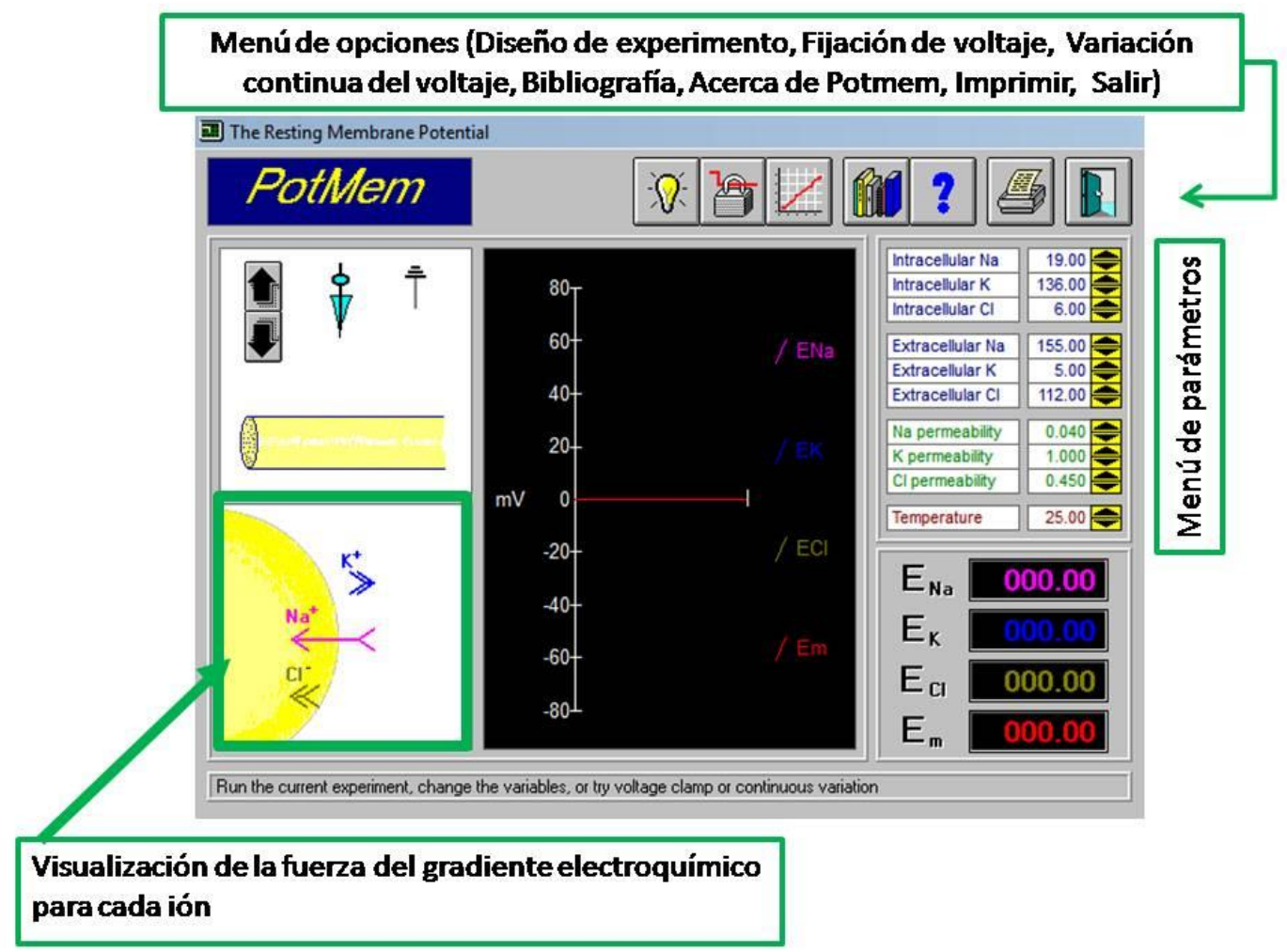

Fig. 1. Vista de la plataforma PotMem (CSoto E., 1989). Fuente: Elaboración propia. 
Dados estos inconvenientes, he complementado los ejercicios sobre PM de reposo con el uso del The NERNST/GOLDMAN equation simulator (@Arizona Board of Regents, 2013). Brevemente, las aportaciones que permite este software sobre el PotMem son: 1) que se pueden realizar cambios de los parámetros de modo que se analizan, en pestañas por separado, el potencial de equilibrio (aunque sólo un ión a la vez) y el Vm celular; 2) En el gráfico de Vm-tiempo se muestra el trazo, en tiempo real, del potencial de equilibrio de Nernst calculado o del Vm estimado según la ecuación GHK. se puede modificar la escala a la que se quiere visualizar; y se puede modificar la escala (tanto en y como en $\mathrm{x}$ ) de dicho gráfico según lo requiramos para una mejor visualización; y 3) permite hacer 'experimentos' usando las concentraciones iónicas de 1 célula genérica (sólo como punto de partida), 2 células eléctricamente excitables distintas (axón gigante de calamar y músculo esquelético) y 1 célula no nerviosa (eritrocito) (Fig. 2).

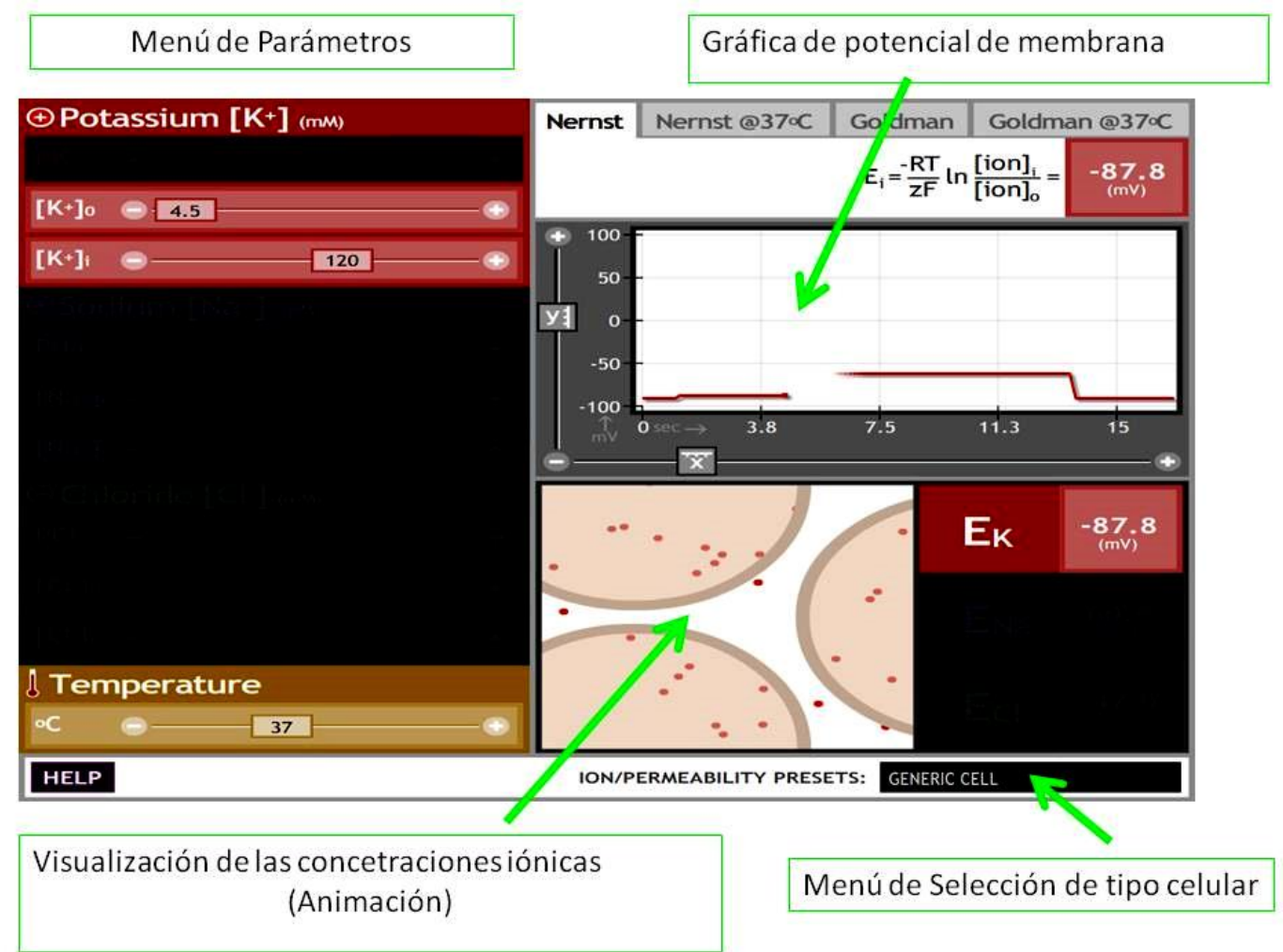

Fig. 2. Vista de la plataforma The NERNST/GOLDMAN equation simulator (CArizona Board of Regents, 2013). Fuente: Elaboración propia. 
Como se observa resulta fundamental la preparación educativa de ambas figuras (docente estudiante) para la aplicación correcta de las nuevas tecnologías de la educación. De lo contrarío se corre el peligro de que se presenten "incongruencias" en esta la revolución pedagógica.

La innovación pedagógica deberá incluir herramientas didácticas (innovaciones tecnológicas) que le permitan al docente diseñar actividades de aprendizaje de calidad para los estudiantes, esto en el marco de modelos constructivistas y colaborativos (Tejedor, García-Valcárcel y Prada, 2009).

\section{Conclusiones}

El uso de imágenes fijas, vídeos, animaciones y software de modelos como el PotMem(C) y del The NERNST/GOLDMAN equation simulator (CArizona Board of Regents) en los cursos de fisiología animal y biofísica de la Escuela de Biología han mostrado ser una herramienta útil en la enseñanza, pues permiten que el estudiante incremente sus dimensiones de aprendizaje logrando la comprensión de los principios que subyacen a la generación del potencial de membrana neuronal.

La aplicación de Tecnologías de la Información y Comunicación en las aulas, asociado con adecuadas prácticas educativas permite renovar el proceso pedagógico abonando al aprendizaje contextualizado.

\section{Bibliografía}

Chiang, L., Ow, M., Bravo, F., García de Cortázar, R., Ulloa, S., \& Conte, P. (2011) En Efectos y contribuciones del uso de simuladores sobre el perfil de egreso de alumnos de liceos técnico profesionales, del sector metal-mecánico. [Documento en PDF]. Recuperado de http://www.comunidadescolar.cl/documentacion/FONIDE/Informe\%20FinalLuciano\%20Chiang-PUC-F511012.pdf 
Halliday, D., Resnick, R., \& Walker, J. (2001) Fundamentals of Physics. U.S.A.: John Wiley \& Sons.

Hille B. (1992) Ionic channels of excitable membranes, U.S.A.: Sinauer Associates.

Kandel, E., Schwartz, J.H., \& Jessell, T.M. (2000) Principles of neural science. Ciudad: McGraw-Hill-.

Kahale Carrillo, D.T. (2011) Virtual rooms: Instrumentos de enseñanza en la educación a distancia universitaria. Revista Icono, 9(2), 138-150.

Soto, E. (1989). Computer Simulation For Teaching Membrane Potential Fundamentals. Biomedical Computing, 24, 119-126.

Tejedor, F.J., García-Valcárcel, A. \& Prada, S. (2009). Medida de actitudes del profesorado universitario hacia la integración de las TIC En: Comunicación. Revista Iberoamericana de Comunicación y Educación, 17(33), 117. 